\title{
Microfabric features of microbial carbonates: experimental and natural evidence of mold holes and crusts
}

\author{
Ya-Sheng $\mathrm{Wu}^{1,2,3}$, Hong-Xia Jiang ${ }^{4^{*}}$, Ying $\mathrm{Li}^{1,3}$ and Gong-Liang Y $\mathrm{u}^{5}$
}

\begin{abstract}
Results of our study based on examination of induced precipitation of carbonate by a cyanobacterium, Lyngbya in the laboratory, and the analyses of microphotographs of both modern and ancient microbial carbonates, demonstrated the importance of recognition of mold holes and carbonate crusts in understanding microbial carbonates. In the experiment, only cyanobacteria Lyngbya can induce precipitation of carbonate, forming scattered grains on the surface of Lyngbya filaments. Carbonate crusts enclosing the old parts of the filaments were formed through aggregation of these scatter grains while mold holes were formed after decay of the filaments. Mainly based on the experiment, six different ways of microbial carbonate formation were recognized: (1) trapping without mold holes, (2) trapping with mold holes, (3) particle-forming induced-precipitation of carbonate, (4) discrete crustforming induced-precipitation of carbonate, (5) induced precipitation, forming tangled crusts that build a porous construction, and (6) induced precipitation, forming a dense construction. And mold holes and crusts can form in ways (4), (5), and (6). Examination of both modern microbial carbonates from the Shark Bay of Australia, Highborne Cay of Bahamas and the atoll of Kiritimati and the microbialites from the Cambrian dolostone sequence in Tarim, Xinjiang, China all demonstrated the limitation of recognizing only mesofabric features and importance of examining microfabric features for understanding of the genesis of the microbial carbonates and their proper classification. The shape, size and arrangement of the mold holes, crusts, and the features of the minerals filling in pores between the crusts, which are referred as the microfabric features here, are keys to better understand the formation and environments of both modern and ancient microbial carbonates.
\end{abstract}

Keywords: Thrombolite, Stromatolite, Induced calcification, Trapping, Laminite, Proclot

\section{Introduction}

Photosynthetic microbes, particularly cyanobacteria, are recognized as being responsible for massive carbonate precipitations (Grotzinger and Knoll 1999). It is estimated that cyanobacteria are the principal contributors to the production of carbonate rocks during almost $70 \%$ of the Earth history (Altermann et al. 2006). The photosynthesis by cyanobacteria is the most common metabolic process for carbonate precipitation that accounts

\footnotetext{
* Correspondence: 2928984509@qq.com

${ }^{4}$ Institute of Paleontology, Hebei GEO University, Shijiazhuang 050031, Hebei Province, China

Full list of author information is available at the end of the article
}

for about $41 \%$ and $84 \%$ of microbe-induced carbonate precipitation in marine and freshwater environments respectively (Zhu and Dittrich 2016). Modern microbe sequestration of $\mathrm{CO}_{2}$ into microbial carbonate, a byproduct of microbial activities, represents a significant process of carbon removal as a counterweight to the rising $\mathrm{CO}_{2}$ concern in the atmosphere. Metal coprecipitation where $\mathrm{Ca}$ ions are replaced by metal ions in microbial carbonate precipitation has also been used as innovative biotechnology for toxic metal remediation, enhanced oil recovery, and construction restoration (Zhu and Dittrich 2016). Therefore, understanding the precipitation processes of microbial carbonates induced 
by photosynthetic cyanobacteria and their hidden features has applications in exploring the history of the Earth, especially in restoration of the Earth's environmental evolution, exploration of petroleum and metal resources in microbial carbonates, and finding solutions to the increase in carbon emissions.

Microbial carbonates, also called microbialites, are the organosedimentary deposits that are formed by the interaction of benthic microbial communities and detrital or chemical sediments (Burne and Moore 1987). Although the definition of microbialites was not formally proposed until 1987 (Burne and Moore 1987), study of stromatolites, the most common type of microbial carbonates, dates back to 1908 (Kalkowsky 1908). Thrombolite, the second most common type of microbial carbonates, was not recognized until 1967 (Aitken 1967). Differences between thrombolite and stromatolite carbonates are mainly in their meso-fabric structures (fabric here is referring to the arrangement of sedimentary components) with thrombolite lacking the laminae of stromatolite but having mesoscopic clotted internal fabrics consisting of the $\mathrm{mm}$ - to $\mathrm{cm}$-sized clots (Aitken 1967). Microbial carbonates are accretionary structures formed in shallow water by trapping, binding, and cementation of sedimentary grains of biofilms by microorganisms, especially cyanobacteria, and by microbeinduced precipitation of carbonates. Because meso-fabric features are generally larger than $1 \mathrm{~mm}$, and can be directly observed by naked eyes on outcrops or hand specimens, they are well studied and have been used as a base of classification for microbial carbonates in the field (Kennard and James 1986).

While meso-fabric features of microbial carbonates are easy to recognize and important for classification, they are not necessarily formed by microbes. Mesoscopically, the clotted fabric is an uneven fabric that can be attributed to many factors, including diagenesis and is not necessarily a microbial clotted fabric. Both sedimentation and diagenetic processes can form uneven fabrics (Wu et al. 2018). Unfortunately, previous studies of both modern and ancient microbial carbonates have largely focused on the mesofabric features, and their microscopic $(<1 \mathrm{~mm})$ and ultramicroscopic features $(<50 \mu \mathrm{m})$ have been given little attention despite their frequent illustrations in some studies (Kennard and James 1986; Shapiro and Awramik 2000). This is evidenced by the usage of only mesofabric features - laminated, clotted, dendritic, and homogeneous fabrics for the classification of microbial carbonates: stromatolites, thrombolites, dendrites, and leiolites, though some with slightly different categories (Riding 1991, 2011; Reid et al. 1999; Dupraz et al. 2009; Chen et al. 2014; Grotzinger and AlRawahi 2014; Lee et al. 2014; Liu et al. 2016; Theisen and Sumner 2016). Lack of recognition of microfabric textures in microbial carbonates can result in inaccurate understanding of microbial carbonate genesis and hinder the reconstruction of their paleoenvironments. Therefore, current study was to examine formation and basic features of the microfabrics of microbial carbonates, including laboratory experiment of precipitation of carbonates by cyanobacteria, microfabrics of microbial carbonates inferred from the revised formation models derived from the experiment, and examination of modern and ancient microbial carbonate examples. The result of the study will help better understand the microscopic features of microbial carbonates, which will likely contribute to understanding of the recognition and classification of microbial carbonates and interpretation of their formation mechanisms and environments.

\section{Data collection and research methods}

\subsection{Laboratory carbonate precipitation by cyanobacteria experiment}

The microbe-induced calcification experiment was conducted at the Institute of Geology and Geophysics, Chinese Academy of Sciences from July to October 2018. A $30 \times 50 \times 30 \mathrm{~cm}^{3}$ plastic box with no cover was used as the container, and was filled with $10 \mathrm{~cm}$ thick of natural soil, and tap water was added to make the water depth reach $10 \mathrm{~cm}$. There was no artificial addition of microbial strains in this experiment, so the microbes all developed from the microbial strains in the soil. The box was put outside and under sunlight, at the temperature of $22-35^{\circ} \mathrm{C}$. Samples of the filamentous microbes were observed under microscope and some of the filaments with carbonate minerals were observed with scanning electron microscope (SEM).

\subsection{Observation of modern microbial carbonates}

Modern microbial carbonates are forming at Shark Bay (Australia), Highborne Cay (Bahamas), the atoll of Kiritimati (Pacific Ocean), and many other localities around the world. We analyzed the microfabrics of microbial carbonates based on the photomicrographs in published literatures. The first selected site was from Hamelin Lagoon at Shark Bay, Australia (Reid et al. 2003; Jahnert and Collins 2011; Suosaari et al. 2016). The second selected site was from Highborne Cay, Bahamas (Riding 1991; Reid et al. 1995; Planavsky and Ginsburg 2009), and the third selected site was from the atoll of Kiritimati, an island in the Pacific Ocean, where microbial carbonates are forming in shallow hypersaline lakes (reported by Arp et al. 2012).

Examining modern microbial carbonates is due to concerns of possible alteration in fabrics and composition of ancient microbial carbonates by various diagenetic processes through the geological time. 


\subsection{Examination of ancient microbialites}

Microfabrics of ancient microbialites were examined from an interval of thin-bedded dolostone and dolostone mounds of the Xiaoerblak Formation (Cambrian Stage 3) at Sugaitblak, southwest of Aksu, Xinjiang, NW China. The Xiaoerblak Formation is $187 \mathrm{~m}$ thick and consists entirely of dolostones. Detailed stratigraphic study of this site has been well documented in previous studies (Song et al. 2012; Bai et al. 2017; Deng et al. 2018; Zheng et al. 2019). More than 100 thin sections were made and examined under the microscope. This site was selected because we considered the carbonate samples from here being a representation of the microbial carbonates of that geological period, given the similar depositional environment of Pan-continent during the Cambrian Period. The selection of the Cambrian Period is because it is the first period of Phanerozoic and an important period of the Earth's evolution. The Stage 3 and lower Stage 4 of the Cambrian (520 512 $\mathrm{Ma}$ ) is the main period of biological explosion (Zhang et al. 2014). Many microbial carbonates have been found from the Cambrian over the world (Wang et al. 1990; Chen et al. 2014, 2018; Ezaki et al. 2017; Wu et al. 2017; Yan et al. 2017). The Cambrian strata from this site in the Tarim Plate are mostly dolostones, and are important oil and gas reservoirs (You et al. 2014).

\section{Results}

\subsection{Precipitation of microbial carbonate from} cyanobacterium growth and formation of mold holes

One week after the starting of the experiment, dark bluish microbial filaments appeared on the soil in the plastic box, which were sampled and identified under the microscope and scanning electron microscope (SEM), including cyanobacterium Lyngbya and filamentous green alga Ulothrix. Fourteen days later, scattered carbonate grains appeared on the surface of the sheaths of some Lyngbya filaments (Figs. 1b-d, e, g, h and 2a, b). Twenty-three days later, carbonate grains appeared on more filamentous sheaths. Thirty-five days later, some filaments were completely covered by carbonate (lower right corner of Figs. If and 2c, d). Only Lyngbya filaments have carbonate on their surface, all on their sheaths, instead of within their sheaths. No green alga filaments have minerals on their surface. No young small filaments and distal ends of Lyngbya filaments have carbonate. The carbonate crusts on the filaments do not have even thickness. In the deep autumn, as the temperature dropped to $<15^{\circ} \mathrm{C}$, the microbes stopped growth. Not all microbes have carbonate minerals on their surfaces. Only cyanobacterium Lyngbya filaments formed carbonate on the surface of their sheaths, but not within their sheaths. The continual accretion of the induced precipitation of carbonate minerals on some filaments formed the crusts enclosing the sheaths. The mold holes formed after the filaments died and decayed.

\subsection{Detailed models of microbial carbonate and mold hole formation}

Based on our observation of the microbe-induced precipitation experiment, in combination with previous researches (Burne and Moore 1987; Reid et al. 2000; Arp et al. 2001; Dupraz et al. 2009), three main models of microbial carbonate and mold hole formation are recognized here (Fig. 3).

\subsubsection{Lime micrite and particle aggregation from trapping}

The trapping refers to the baffling and protecting of carbonate sediments by microbial mats. The baffling causes micrites or lime micrites and particles carried by currents to be deposited while the protecting prevents the sediments deposited between microbes from being washed away by currents. Two opposite cases exist in the sediment aggregation. (1) The sediments between the microbes fail to become consolidated or semiconsolidated before the decomposition of the microbes, and the microbes may leave no holes in the sediments after their decay (Fig. 3a1-a3). The sediments formed thus are not significantly different from those deposited from currents by gravity, and thus are difficult to recognize. (2) The sediments become consolidated or semi-consolidated before the decomposition of the microbes as a result of cementation, or dehydration due to exposure to the air. After decay, the microbes leave holes in the sediments, i.e., the mold holes, which cause an uneven feature of the sediments (Fig. 3b1-b3). The sediments form stromatolites if there is a laminated fabric caused by the arrangement of the mold holes or other reasons, otherwise, they form thrombolites.

\subsubsection{Microbe-induced precipitation}

The physiological activity of microbes, mainly photosynthesis, causes the changes in the properties of the surrounding water, including rise in $\mathrm{pH}$, and leads to the precipitation of carbonate minerals. Our observations indicate that the carbonates formed by this action are generally attached to the surface of the microbes, beginning with scattered grains, to clusters and eventually forming crusts enveloping the microbes. The precipitation occurs in four different ways: (1) it forms scattered carbonate grains on microbe surface, which drop to the seafloor as micrites or grains after the microbes die and decompose (Fig. 3c1-c3); (2) it forms carbonate crusts enclosing microbes, which leave mold holes after the microbes die and decompose and form loose sediments; (3) the adjacent crusts are mostly interconnected or tangled, and form an in-situ carbonate construction with abundant microscopic inter-crust pores (Fig. $3 \mathrm{~d} 1-\mathrm{d} 3$ ); and (4) the 

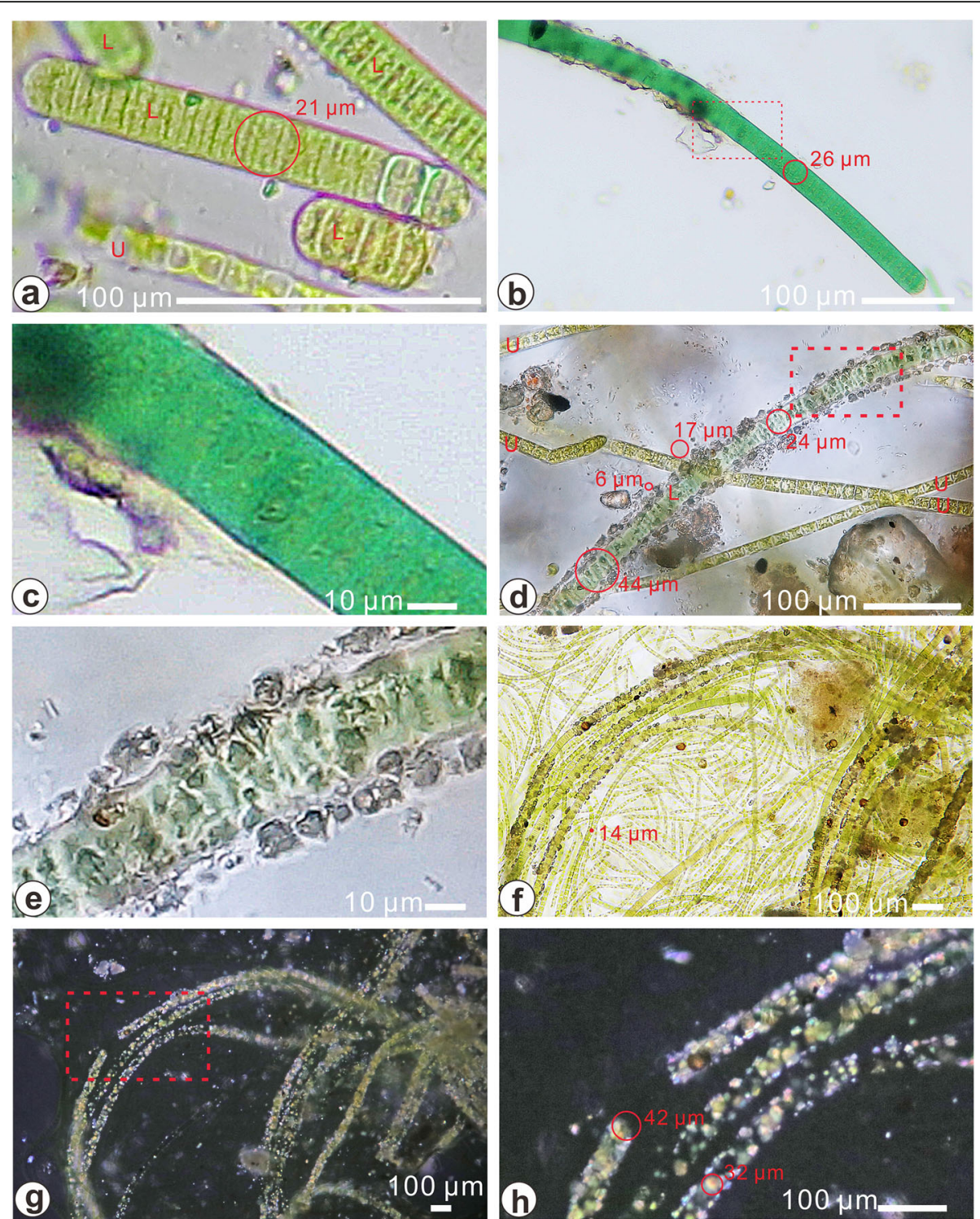

Fig. 1 Photomicrographs of cyanobacteria and green algae in an experiment showing induced precipitation of carbonate from scattered calcite grains on sheaths to crusts enclosing filaments, with their diameters marked by red circles/dots. a Four thick young filaments of cyanobacterial Lyngbya ("L") without induced carbonate, and a thin filament of green alga Ulothrix ("U"); b A cyanobacterial filament (Lyngbya), whose left part has scattered carbonate grains; c Enlargement of the red box in $\mathbf{b}$; $\mathbf{d}$ A filament of Lyngbya ("L"), whose sheath is covered with carbonate grains, and four filaments of Ulothrix ("U"); e Enlargement of the red box in $\mathbf{d}$; $\mathbf{f}$ Seven Lyngbya filaments with carbonate grains, two Lyngbya filaments free of carbonate, and many yellow-greenish filaments of Ulothrix, with a Lyngbya filament in the lower right corner completely covered by carbonate; $\mathbf{g}$ More than 10 cyanobacterial filaments with calcite grains on their surfaces; $\mathbf{h}$ Enlargement of the red box in $\mathbf{g}$, the interference color is high white, indicative of calcite or aragonite. a-f: Plane-polarized light images; $\mathbf{g}, \mathbf{h}$ : Cross-polarized light images

inter-crust spaces are completely filled by carbonate and form a dense microbial carbonate construction, when there is sufficient time for the crusts to grow (Fig. 3e1e3).

\subsubsection{Bio-controlled calcification}

Bio-controlled calcification refers to the process that carbonate accumulates inside organisms to form skeletons with specific shapes and structures during physiological activities of the organisms. For example, the physiological action of cyanobacteria can cause formation of carbonate within their sheaths, and form tube walls with even thickness preserving the shape and size of the cyanobacteria (Fig. 3f1-f3). This was also reported in the calcified filaments of cyanobacterium Plectonema in the Aldabra Atoll of the Indian Ocean (Riding 1977) which will be discussed in next section. 

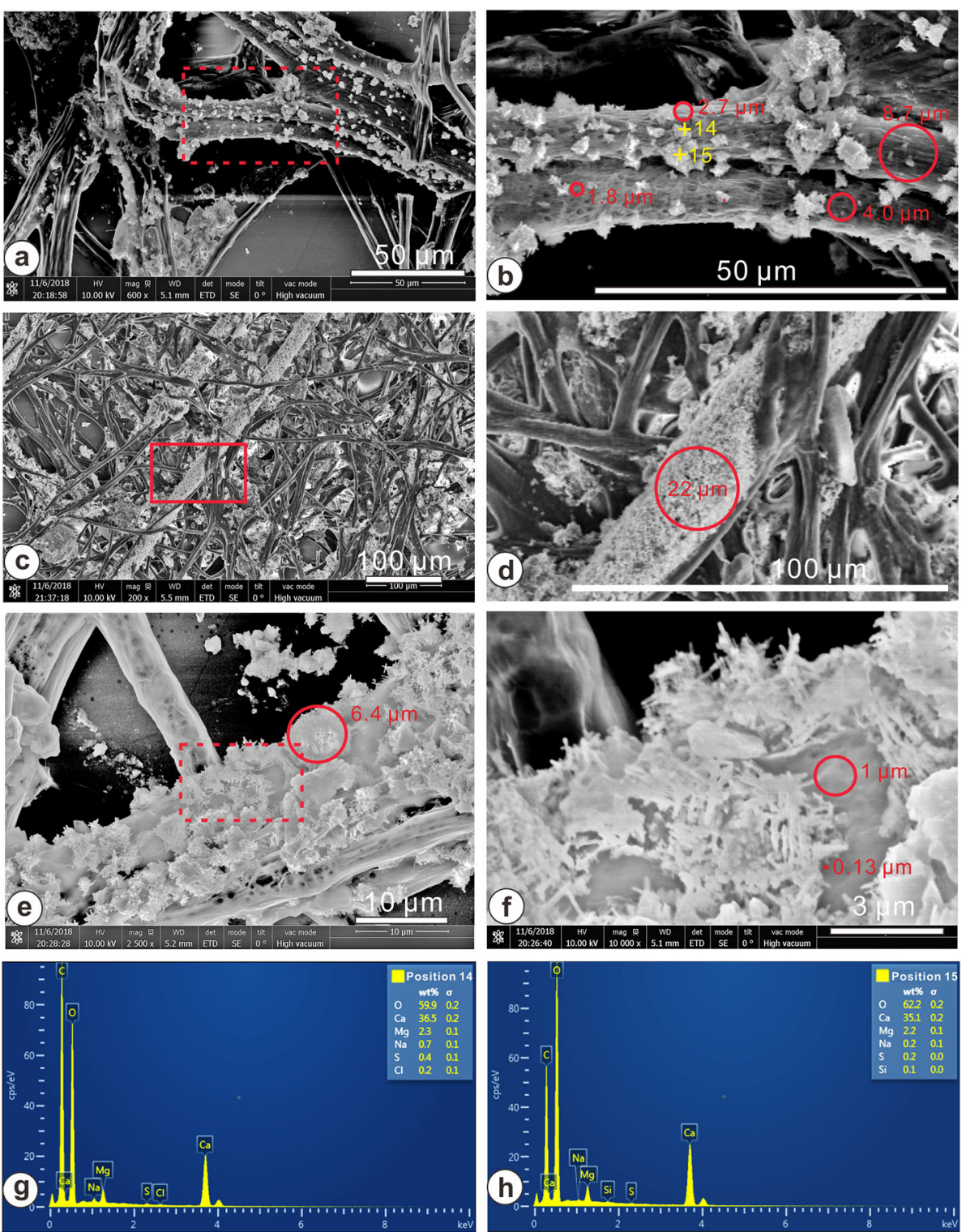

Fig. 2 Scanning electron microscope (SEM) images of cyanobacterial Lyngbya filaments and energy spectrum charts of carbonates, with green alga filaments (diameter $<10 \mu \mathrm{m}$ ); the same samples as of Fig. 1. Diameters are marked by red circles/dots. a Four filaments with scattered carbonate grains on their surfaces; $\mathbf{b}$ Enlargement of the red box in $\mathbf{a} ;+$ : positions of energy spectrum tests; $\mathbf{c}$ Three filaments covered by carbonate grains; $\mathbf{d}$ Enlargement of the red box in $\mathbf{c}$; e Carbonate grains on the surface of a filament; $\mathbf{f}$ Enlargement of the red box in $\mathbf{e}$, showing carbonate grains consisting of rod-shaped crystals which are $0.1 \times 1 \mu^{2}$ in size; $\mathbf{g}, \mathbf{h}$ Energy spectrum charts of the positions 14 and 15 in $\mathbf{b}$

\subsection{Microfabric features - mold holes and crusts in modern microbial carbonates}

The first microbial carbonates exampled were stromatolites from Hamelin Lagoon in Shark Bay (Reid et al. 2003; Jahnert and Collins 2011; Suosaari et al. 2016), where the stromatolites were only formed in the lower intertidal and upper subtidal zones. The stromatolites comprise alternating laminae of carbonate and pores (Fig. 4a; Jahnert and Collins 2011, their Fig. 3b). After enlargement, it is clear that the stromatolites show abundant dense mold holes and pale carbonate crusts
(Fig. 4b). The mold holes are round or wormlike, ranging from $125 \mu \mathrm{m}$ to $250 \mu \mathrm{m}$ in diameter, with the surrounding carbonate crusts (in a lighter color) $125 \mu \mathrm{m}$ thick.

The second modern microbial carbonates we examined were thrombolites from the intertidal zone of the lagoon behind the reef and in the shallow subtidal zone in Highborne Cay, Bahamas, as widely explored by previous researchers (Riding 1991; Reid et al. 1995; Planavsky and Ginsburg 2009). Microbial carbonates in Highborne Cay, Bahamas have been considered to be the only 


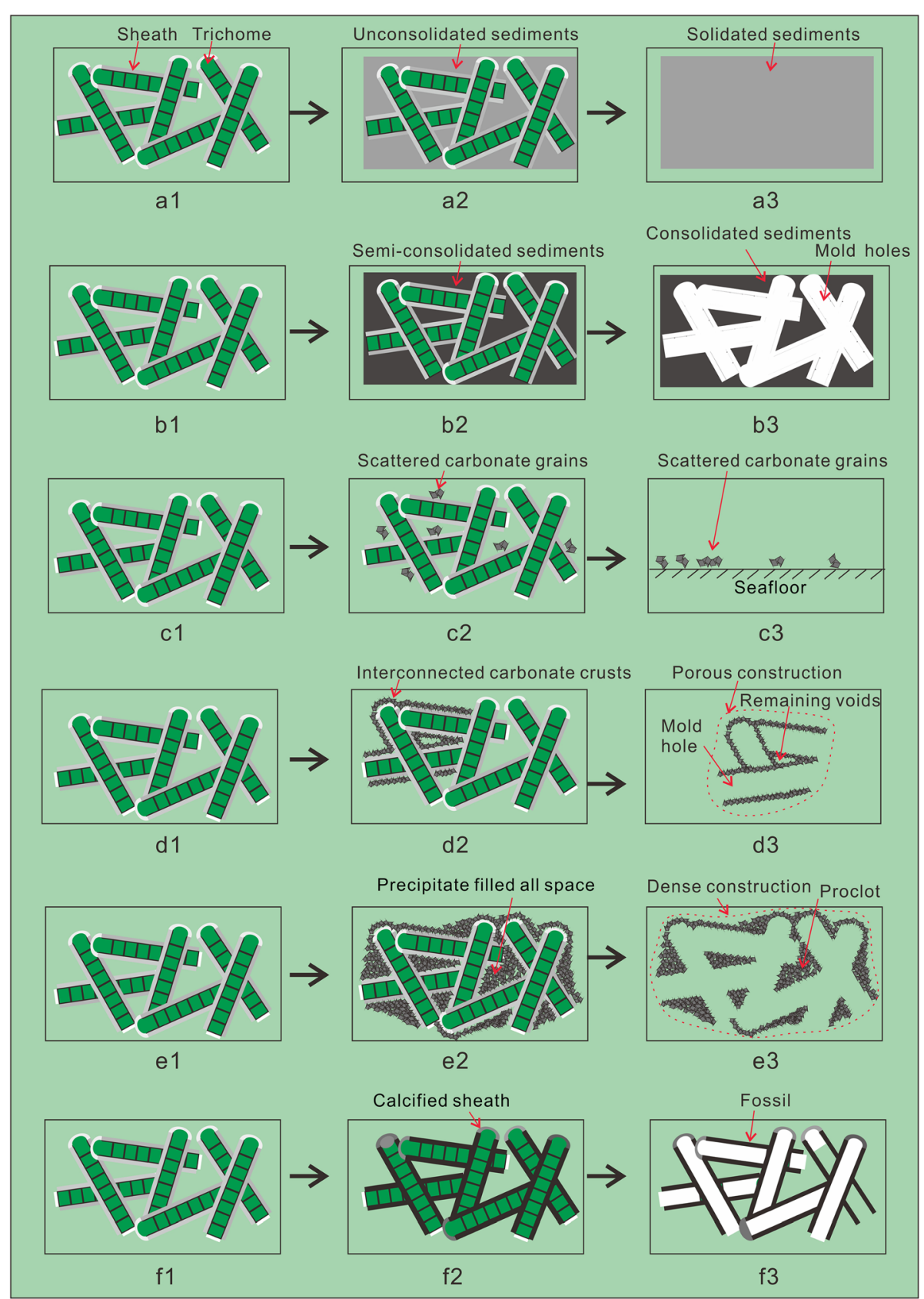

Fig. 3 Models of microbial carbonate formation by filamentous cyanobacteria and formation of mold holes and crusts. a1 to a3, b1 to b3: Trapping lime micrites and particles; $\mathbf{c} \mathbf{1}$ to $\mathbf{c} \mathbf{3}, \mathbf{d} \mathbf{1}$ to $\mathbf{d} \mathbf{3}$, e1 to $\mathbf{e}$ : Biologically-induced precipitation of carbonate; $\mathbf{f 1}$ to $\mathbf{f 3}$ : Bio-controlled calcification. $\mathbf{c} \mathbf{1}$ to $\mathbf{c} \mathbf{3}$ : Scattered calcite grains on microbe surface, or as loose sediments depositing on seafloor; $\mathbf{d} \mathbf{1}$ to $\mathbf{d} \mathbf{3}$ : Microbe-induced precipitation formed crusts enclosing the microbes, and the interspaces between adjacent crusts are not fully filled by carbonate; e1 to e3: Microbe-induced precipitation formed crusts enclosing the microbes, and the interspaces between adjacent crusts are fully filled with carbonate; $\mathbf{f 1}$ to $\mathbf{f 3}$ : Carbonate precipitation is limited within the sheaths, forming walls with even thickness, recognized as fossils if preserved in strata. If the microbial role in the sediments in a3 can be recognized, the sediments belong to microbial carbonate; the carbonates in $\mathbf{b 3}$, c3, d3 and $\mathbf{e 3}$ belong to microbial carbonates; and the carbonate in $\mathbf{f} \mathbf{3}$ belongs to both microbial carbonate and microbial reef. In case of $\mathbf{b}$, mold holes form, and in cases of $\mathbf{d}$ and $\mathbf{e}$, both mold holes and carbonate crusts form

representative of modern microbial carbonates from the shallow marine environments with normal salinity (Patterson 2014). Specimens collected from the surface of the platform retain filamentous microbes and their carbonate crusts (Fig. 4c, d). It is also apparent that many filamentous mold holes are surrounded by pale carbonate crusts. The mold holes ranging from 34 to $43 \mu \mathrm{m}$ in diameters were formed probably by the 

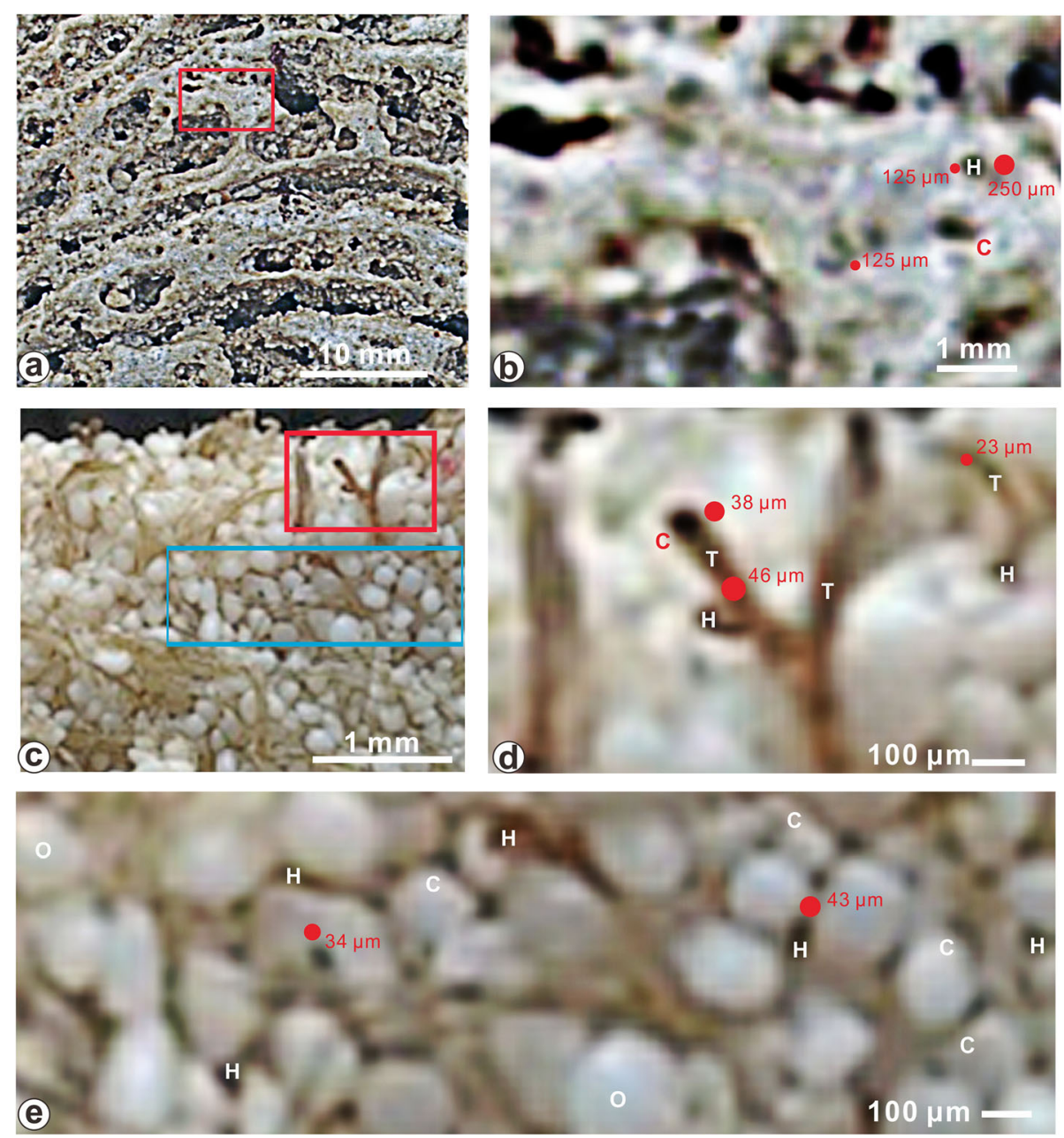

Fig. 4 Microfabric features of modern microbial carbonates from Shark Bay of Australia $(\mathbf{a}, \mathbf{b})$ and the Bahamas $(\mathbf{c}, \mathbf{d}$, e): presence of mold holes and crusts. Diameters are marked by red dots. a Modified from the Fig. 3b of Jahnert and Collins (2011), known as colloform structure, showing laminated microfabric comprising alternating lamellae of carbonate and voids; $\mathbf{b}$ Enlargement of the red box in $\mathbf{a}$, showing that the mold holes $(\mathrm{H})$ are circular or wormlike, with diameters of $125-250 \mu \mathrm{m}$, and surrounded by white carbonate crusts (C) of $125 \mu \mathrm{m}$ thick; c Modified from Fig. 49A of Patterson (2014), hand specimen, oolitic thrombolites, with white ooids and the yellowish and brownish algal filaments between the ooids; $\mathbf{d}$ Enlargement of the red box in c, showing two algal filaments (T) with diameters of $23 \mu \mathrm{m}$ and $46 \mu \mathrm{m}$, respectively, which are enclosed by opalescent carbonate crusts $(\mathrm{C})$ of $38 \mu \mathrm{m}$ thick; e Enlargement of the blue box in c, showing many mold holes $(\mathrm{H})$ and milky-colored carbonate crusts $(\mathrm{C})$ between the white ooids $(\mathrm{O})$, and the diameters of the mold holes are $34-43 \mu \mathrm{m}$

filamentous microbe, Dichothrix, a filamentous cyanobacterium genus that is characterized by false branching at acute angles and includes more than 40 species (Patterson 2014). The mold hole shapes are typically curved filamentous.

The third modern microbial carbonates we examined were from the atoll of Kiritimati, an island in the Pacific Ocean reported by Arp et al. (2012). Microbial carbonates are forming in the shallow hypersaline lakes beneath the orange-yellow microbial mat at the bottoms of the lakes, and are white in color, with a netlike fabric, belonging to thrombolites (Fig. 5a, b). As shown in the photomicrographs (Fig. 5c, d), the microbial carbonates consist of dense mold holes and the carbonate in between. The mold holes are round or wormlike in shape, and have two diameters of $10 \mu \mathrm{m}$ and $19 \mu \mathrm{m}$, respectively. The thickness of the carbonate between the mold holes can reach $19 \mu \mathrm{m}$, which is similar to the diameter of the mold holes.

\subsection{Microfabric features - mold holes and crusts in microbialites of geological periods}

The Cambrian microbial carbonates we examined from the Sugaitblak section in Aksu, Xinjiang, China are macroscopically composed of thin-bedded dolostone and dolostone mounds (Fig. 6a). The mounds range 6-20 m in height, and are massive on the outcrop (Fig. 6a, b). 


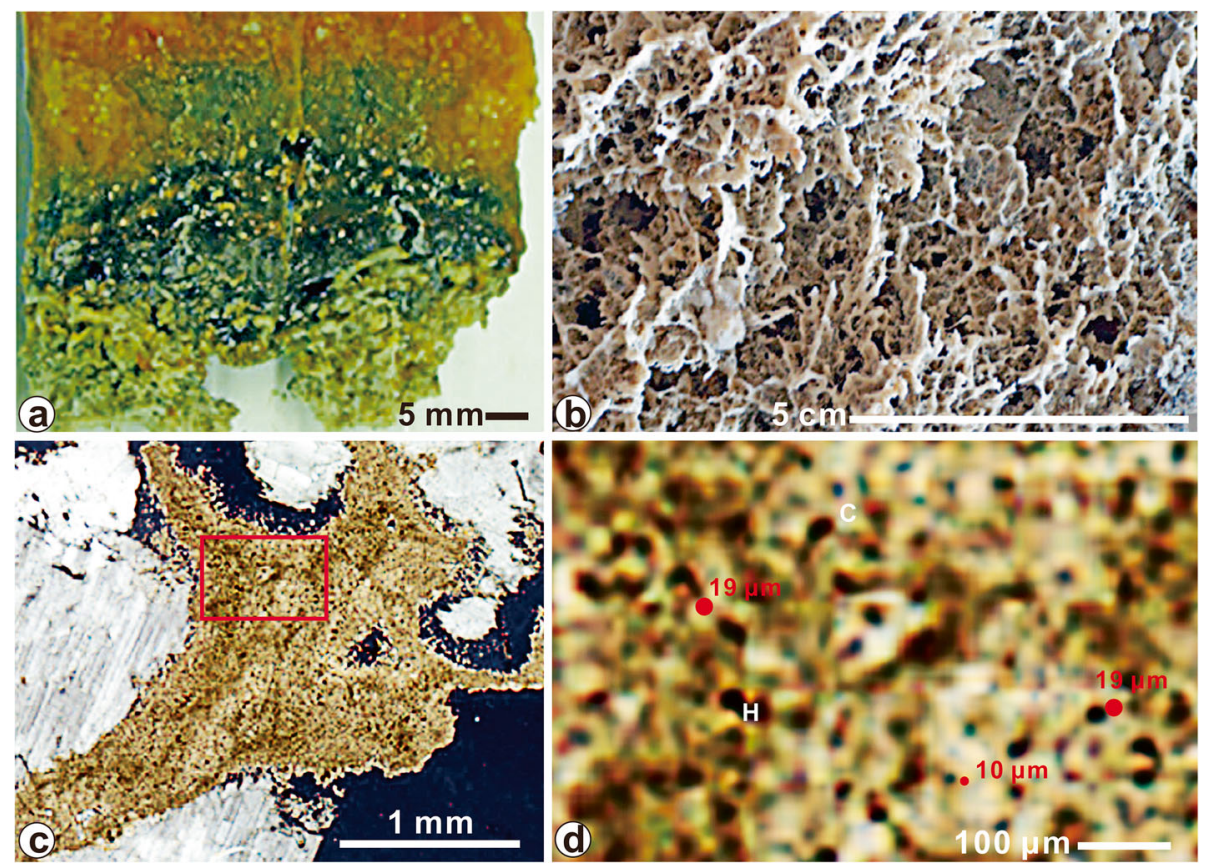

Fig. 5 Microfabric features of the modern microbial carbonates in the hypersaline lakes of atoll of Kiritimati, Pacific Ocean: presence of mold holes and crusts. Diameters are marked by red dots. a Modified from Fig. 6-E of Arp et al. (2012), of a hand specimen collected from the hypersaline lake of atoll of Kiritimati, showing an orange microbial mat in the upper part, dead microbes in the middle part, and white reticulate microbial carbonate in the lower part; b Modified from Fig. 13-B of Arp et al. (2012), of a sample collected from the same location as a, showing white netlike microbial carbonate; c Modified from Fig. 13-F of Arp et al. (2012), photomicrograph of thin section, of a specimen collected from the same place as $\mathbf{a}$; $\mathbf{d}$ Enlargement of the red box in $\mathbf{c}$, showing that the microbial carbonate consists of mold holes $(\mathrm{H})$ with the carbonate $(\mathrm{C})$ in between, and the mold holes are round or wormlike, 10-19 $\mu \mathrm{m}$ in diameter

Under microscope (Fig. 6c, d), the thin section sampled from the mound shows a clotted fabric, consisting of dark irregular net-shaped, speckled, and vermicular "clots" of $44-140 \mu \mathrm{m}$ in width, and the light-colored patches (called bright patches) between the "clots". The diameter of the bright patches can reach $400 \mu \mathrm{m}$.

On further enlarged image (Fig. 6e), the bright patches consist of light-colored dolomite crystals containing mold holes. Most mold holes are curved filamentous in shape; and a few are round with a diameter of $1.0 \mu \mathrm{m}$. The dolomite crystals are subhedral, with a width of $50 \mu \mathrm{m}$ and have visible boundary. The spacing of the mold holes is relatively large, and can reach $15 \mu \mathrm{m}$. The dolomite matrix between the mold holes is white. The light-colored dolomite gives the bright patches a lighter color. The filamentous mold holes represent filaments of microbes. The sparsity of the mold holes in the "bright patches" indicates that the environmental conditions had changed before the remaining voids between the filaments were filled. During the dolomitization stage, euhedral and subhedral dolomite crystals formed, each enclosing several mold holes.

On contrary to the "bright patches", the dark "clots" consist of more mold holes and much smaller dolomite crystals (Fig. 6f), and in addition inter-crystalline pores.
The mold holes are similar to those in the "bright patches" in size and shape. The dense mold holes represent once presence of dense microbes. Two factors, i.e., more mold holes and more pores, make the "clots" darker in color. We suspect that these mold holes were left by species similar to Geitlerinema ionicum, an extant marine filamentous cyanobacterium because the diameter and length of these mold holes are similar to those of the filaments of Geitlerinema ionicum (Wang et al. 2017).

\section{Discussion}

Cyanobacteria are recognized for its ability to promote the calcium carbonate precipitation (Riding 2006). The increased alkalinity resulting from the sulfate reduction and the $\mathrm{Ca}^{2+}$ released from cyanobacterial extracellular polymeric substances lead to the $\mathrm{CaCO}_{3}$ precipitation (Dupraz et al. 2009). The forms of the microbial carbonates, including stromatolites and thrombolites, are a result of calcification by microbial mats and biofilms, commonly dominated by cyanobacteria (Arp et al. 2001). Both the saturation state of seawater with respect to calcium carbonate (Webb 2001) and the biomineralization processes (Bosscher and Schlager 1993) that control the 

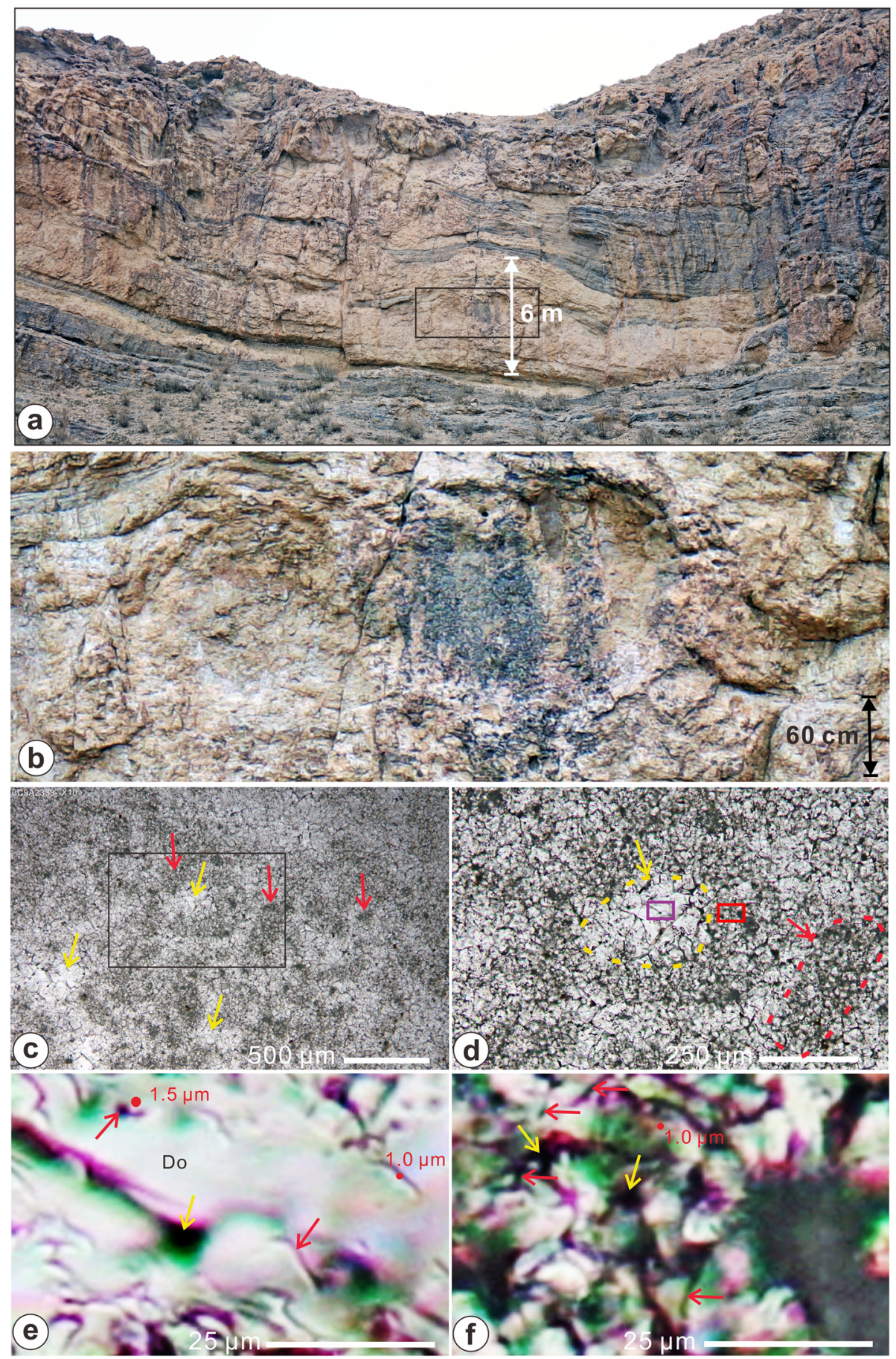

Fig. 6 Microfabric of the microbial carbonate of the Cambrian Stage 3 at Sugaitblak section, Aksu, Tarim, Xinjiang, NW China: presence of mold holes and crusts. a An outcrop with microbial mounds, which are mound-like, massive, composed of dolostone, and are surrounded by thinbedded dolostone; $\mathbf{b}$ Enlargement of the black box in $\mathbf{a}$; $\mathbf{c}$ Thin section of a specimen from the outcrop in $\mathbf{b}$, consisting of dark wormlike and netlike "clots" (red arrows) and the bright patches of dolomite crystals (yellow arrows) between the "clots"; $\mathbf{d}$ Enlargement of the black box in $\mathbf{c}$ with "clots" (outlined by a red dotted circle) and bright patches (outlined by a yellow dotted circle); e Enlargement of the purple box in $\mathbf{d}$, which is part of a dolomite crystal (Do) with a few filamentous mold holes (red arrows) of 1-1.5 $\mu \mathrm{m}$ in diameter; $\mathbf{f}$ Enlargement of the red box in $\mathbf{d}$ consisting of smaller dolomite crystals, more filamentous mold holes (red arrows) and rich inter-crystalline black pores (yellow arrows) 
marine carbonate precipitation can be reflected in their microfabric features of mold holes and crusts.

\subsection{Microfabric features - crusts and mold holes are basic features of microbial carbonates}

Many experiments have been done on mineral precipitation induced by microbes (Obst et al. 2009; Kranz et al. 2010; Couradeau et al. 2012; Liang et al. 2013; Bundeleva et al. 2014; Yan et al. 2014; Han et al. 2017). However, they all were performed in artificially prepared solutions or on agars. Unlike previous studies, our experiment was carried out on the conditions which were very similar to those of the modern microbial carbonates in natural environments. There was no artificial addition of microbial strains in this experiment and the microbes all developed from the microbial strains in the soil.

Our experiment confirmed that microbe-induced precipitation of carbonate crusts and formation of mold holes are common microfabric features recognizable in naturally-formed microbial carbonates. However, not all microbes (e.g., the green alga Ulothrix) have carbonate minerals on their surfaces; only Lyngbya filaments in our experiment have carbonate on their sheath surface, which can form crusts enclosing the sheaths. Because the uneven mineral crusts are formed on only the sheath surface, i.e., not within the sheaths, they are not considered as fossils. However, Riding (1977) observed the formation of carbonate minerals within the sheaths of cyanobacterium Plectonema filaments, which enables them to be preserved as fossils. The factors controlling the site of the precipitation (whether within the sheath or on the sheath surface) are still unknown.

\subsection{Inferred microfabric features of microbial carbonates from models}

Microbialite is defined to have an origin controlled by benthic microbial communities (Burne and Moore 1987; Riding 2011). The usage of microbial carbonate in this paper includes not only microbialites but also those microbial carbonates having an origin controlled by planktic microbes. The biological influences of microbes on the formation of carbonates have been discussed by many researchers (Lowenstam and Weiner 1989; McConnaughey 1989; Kaźmierczak et al. 2015), which were divided into three kinds: biologically induced, biologically influenced or biologically controlled (Dupraz et al. 2009). Biologically-induced formation refers to the precipitation of carbonates due to the change in surrounding microenvironments caused by microbes, such as rise in $\mathrm{pH}$ values caused by taking in $\mathrm{CO}_{2}$ by cyanobacteria. Biologically-influenced carbonate formation refers to the formation of carbonates in which biological properties of the organisms affect the shape and composition of the minerals. Our revision of the formation models of microbial carbonates (Fig. 3), i.e., the two types of trapping, four types of microbe-induced precipitation and the bio-controlled calcification, further detailed the formation ways of microbial carbonates, especially recognized the presence of crusts and mold holes in almost all microbial carbonates, and provided more enriched information on possible variations of each process.

It is noticed that induced precipitation is a gradual process, needing a longer period of time. Given the same other conditions, the formation types of microbial carbonates depend on the stages of the precipitation. The growth rate, shape, sizes of crusts and mold holes are indicators of the environmental temperature, light, nutrient levels and water chemical conditions where they form. All the formation models show that in most cases, the microbes leave dense and a variety of mold holes and crusts of different thickness within the microbial carbonates depending on the conditions. The shapes of mold holes depend on both filamentous and nonfilamentous microbes and the precipitation rate of the induced carbonates.

\subsection{Microfabric features of microbial carbonates in modern environments}

It is clear that the mold holes and carbonate crusts in the modern microbial carbonates from three different locations have different shapes and sizes. Their varied features reflect their uneven distribution of microbes, and different conditions of the substrate and the duration of the suitable environmental conditions for growth of these microbes. They also reflect the composition of the microbial mat, and the physical and chemical conditions of the environments these microbes grow in. In modern stromatolites and thrombolites, the mold holes and carbonate crusts display a wide range of microstructures including micropeloidal, densely micritic, or agglutinated microfabrics (Riding 1991; Dupraz and Strasser 1999).

\subsection{Importance of recognizing microfabrics in microbial carbonates of geological time}

The results of our study on the Cambrian microbial carbonates from Xinjiang, China clearly demonstrate the possibility of mis-classification and mis-interpretation of microbial carbonates and their forming environments if the ultramicroscopic mold holes and carbonate crusts were not examined. The limitation of the mesofabricfocused studies was also shown by previous studies of the $\mathrm{P}-\mathrm{T}$ boundary microbial carbonates in South China. The P-T boundary carbonate microbialite outcrops in South China consist of dark patches several millimeters to centimeters widely distributed among light patches, and often have a speckled, reticulate or dendritic appearance, looking like a typical clotted fabric. Because they 
appear to have a clotted mesofabric, many researchers interpreted them as thrombolites (Ezaki et al. 2003, 2008; Kershaw et al. 2007, 2012; Liu et al. 2007; Wang et al. 2012), although some considered them a carbonate construction (Wang et al. 2005; Yang et al. 2006). A detailed study of the thin sections by $\mathrm{Wu}$ and others (Jiang and Wu 2007; Wu et al. 2014, 2018), however, revealed that the dark patches on outcrop are actually light-colored in thin sections, and are composed of coarser dolomites and blocky calcite cements that are mainly formed by diagenesis; while the light patches on outcrop are darker in color in thin sections, and are composed of micritic sediments with some small gastropod and ostracod fossils. By definition, the fossil-bearing sediments are definitely not clots. As the dark patches are cements, instead of microbial micrites, they don't belong to clots. The dark patches on outcrop of these carbonates were formed from altered mold-casting fossils of the cyanobacterium Microcystis colonies through a series of diagenetic processes and are, therefore, not thrombolites (Wu et al. 2014).

Features of different scales have different significances. The microfabrics on the scale of $50-1000 \mu \mathrm{m}$ reflect the uneven distribution of microbes, which is determined by the conditions of the substrate and the duration of the suitable environmental conditions for growth of microbes. The ultra-microfabrics on the scale of $1-50 \mu \mathrm{m}$ reveal the composition of the microbial mat, the possible source of precipitation and other factors that reflect detailed information on the carbonate diagenesis.

Microscopic features such as the shape and width of the microclots and the light-colored patches in between in the Tarim Cambrian thrombolite need to be examined under microscope. In addition, the ultramicroscopic features (which will need to be examined under a high-power microscope), i.e., the shape and size of the mold holes and the features of the minerals between the mold holes, also need to be examined when the understanding of the diagenesis of the microbial carbonates is important. The original definition of mesoclot refers to the micritic framework between pores or sediments (Aitken 1967; Kennard and James 1986; Shapiro and Awramik 2000). The mesoclots in the thrombolite in the Tarim Cambrian section, however, consist of microclots and the bright patches in between, instead of only micrites. Therefore, the definition of the term mesoclot does not reflect the actual situation. The microscopic "clots", i.e., microclots, of the Tarim Cambrian thrombolite are actually not clots either: they consist of smaller basic units - the mold holes, and the carbonate or mineral fillings between the mold holes, instead of only micrites.

\section{Conclusions}

Experiments in this paper show that induced precipitation of carbonates occurs only on the surface of some microbes in sequence, from scattered mineral grains, clustered mineral grains, to eventually visible crusts enclosing most parts of the filaments. On microscopic or ultramicroscopic scale, the basic components of microbial carbonates are the mold holes, crusts, filling minerals and various voids, with mold holes and crusts as the basic features of the newly-formed microbial carbonates. The mold holes and crusts are the common basic features observed in the modern microbial carbonates from the atoll of Kiritimati in the Pacific Ocean, Shark Bay in Australia, and Highborne Cay in Bahamas. In addition, mold holes are also common feature in the "clots" and "bright patches" from the thrombolite mound in the ancient carbonates as shown in the samples from Tarim Basin, China. Because ultra-microfabric features, including mold holes and crusts, are the basic components of microbial carbonates and can only be observed microscopically, they should be included in the study of microbial carbonates for better understanding the genesis of microbial carbonates and their proper classifications.

\section{Abbreviation \\ SEM: Scanning electron microscope}

\section{Acknowledgements}

We are grateful to Professors Hong-Bing Sun, to Gernot Arp and Robert Burne for providing high-quality pictures of modern microbial carbonates, and to Professor Robert Riding for his helpful advice.

\section{Authors' contributions}

YSW designed the experiment and study on the microscopic and ultramicroscopic features of the modern and ancient microbial carbonates. $H X J, Y L$ and GLY performed the study. YSW and HXJ wrote the manuscript. $Y L$ and GLY revised the manuscript. All authors read and approved the final manuscript.

\section{Funding}

This study was supported by the National Natural Science Foundation of China (Grant No. 41972320), National Major Science and Technology Projects of China (Grant No. 2016ZX05004-004) and the Strategic Priority Research Program (B) of Chinese Academy of Sciences (Grant No. XDB26000000) to Ya-Sheng Wu.

\section{Declarations}

\section{Competing interests}

The authors declare that they have no competing financial interests or personal relationships that could have appeared to influence the work reported in this paper.

\footnotetext{
Author details

${ }^{1}$ Key Laboratory of Cenozoic Geology and Environment, Institute of Geology and Geophysics, Chinese Academy of Sciences, Beijing 100029, China. ${ }^{2}$ Innovation Academy for Earth Science, Chinese Academy of Sciences, Beijing 100029, China. ${ }^{3}$ University of Chinese Academy of Sciences, Beijing 100049, China. ${ }^{4}$ Institute of Paleontology, Hebei GEO University, Shijiazhuang 050031, Hebei Province, China. Institute of Hydrobiology, Chinese Academy of Sciences, Wuhan 430072, Hubei Province, China.
} 
Received: 14 January 2021 Accepted: 29 June 2021

\section{Published online: 26 July 2021}

\section{References}

Aitken, J.D. 1967. Classification and environmental significance of cryptalgal limestones and dolomites, with illustrations from the Cambrian and Ordovician of southwestern Alberta. Journal of Sedimentary Petrology 37 (4): 1163-1178. https://doi.org/10.1306/74D7185C-2B21-11D7-86480001 02C1865D

Altermann, W., J. Kazmierczak, A. Oren, and D.T. Wright. 2006. Cyanobacterial calcification and its rock-building potential during 3.5 billion years of Earth history. Geobiology 4 (3): 147-166. https://doi.org/10.1111/j.1472-4 669.2006.00076.x.

Arp, G., G. Helms, K. Karlinska, G. Schumann, A. Reimer, J. Reitner, and J. Trichet. 2012. Photosynthesis versus exopolymer degradation in the formation of microbialites on the atoll of Kiritimati, Republic of Kiribati, Central Pacific. Geomicrobiology Journal 29 (1): 29-65. https://doi.org/1 0.1080/01490451.2010.521436.

Arp, G., A. Reimer, and J. Reitner. 2001. Photosynthesis-induced biofilm calcification and calcium concentrations in Phanerozoic oceans. Science 292 (5522): 1701-1704. https://doi.org/10.1126/science.1057204.

Bai, Y., P. Luo, S. Wang, C.M. Zhou, X.F. Zhai, S. Wang, and Z.Y. Yang. 2017. Structure characteristics and major controlling factors of platform margin microbial reef reservoirs: A case study of Xiaoerbulak formation, lower Cambrian, Aksu area, Tarim Basin, NW China. Petroleum Exploration and Development 44 (3): 377-386. https://doi.org/10.1016/S1 876-3804(17)30044-7.

Bosscher, H., and W. Schlager. 1993. Accumulation rates of carbonate platforms. The Journal of Geology 101 (3): 345-355. https://doi.org/10.1 086/648228.

Bundeleva, I.A., L.S. Shirokova, O.S. Pokrovsky, P. Bénézeth, B. Ménez, E. Gérard, and S. Balor. 2014. Experimental modeling of calcium carbonate precipitation by cyanobacterium Gloeocapsa sp. Chemical Geology 374375: 44-60. https://doi.org/10.1016/j.chemgeo.2014.03.007.

Burne, R.V., and L.S. Moore. 1987. Microbialites: Organosedimentary deposits of benthic microbial communities. Palaios 2 (3): 241-254. https://doi. org/10.2307/3514674.

Chen, J.T., J. Lee, and J. Woo. 2014. Formative mechanisms, depositional processes, and geological implications of Furongian (Late Cambrian) reefs in the North China platform. Palaeogeography, Palaeoclimatology, Palaeoecology 414: 246-259. https://doi.org/10.1016/j.palaeo.2014.09.004.

Chen, M., C.T. Xiao, J. Cheng, X.L. Hu, and D.Q. Sun. 2018. Sedimentary characteristics of stromatolites in Cambrian strata in Songzi Liujiachang area and its paleoenvironmental significance. Open Journal of Yangtze Oil and Gas 3 (2): 79-92. https://doi.org/10.4236/ojogas.2018.32007.

Couradeau, E., K. Benzerara, E. Gérard, D. Moreira, S. Bernard, G.J. Brown, and P. López-García. 2012. An early-branching microbialite cyanobacterium forms intracellular carbonates. Science 336 (6080): 459-462. https://doi. org/10.1126/science. 1216171.

Deng, S.B., P. Guan, B.H. Li, P.X. Liu, and Y.Q. Chen. 2018. Sedimentary texture and formation process of the Lower Cambrian platform marginal zone in the Tarim Basin, NW China. Acta Sedimentologica Sinica 36 (4): 706-721. https://doi.org/10.14027/j.issn.1000-0550.2018.059 (in Chinese with English abstract).

Dupraz, C., R. Pamela Reid, O. Braissant, A.W. Decho, R.S. Norman, and P.T. Visscher. 2009. Processes of carbonate precipitation in modern microbial mats. Earth-Science Reviews 96 (3): 141-162. https://doi.org/10.1016/j.ea rscirev.2008.10.005

Dupraz, C., and A. Strasser. 1999. Microbialites and micro-encrusters in shallow coral bioherms (middle to late Oxfordian, Swiss Jura Mountains). Facies 40 (1): 101-129. https://doi.org/10.1007/BF02537471.

Ezaki, Y., J.B. Liu, and N. Adachi. 2003. Earliest Triassic microbialite micro- to megastructures in the Huaying area of Sichuan Province, South China: Implications for the nature of oceanic conditions after the end-Permian extinction. Palaios 18 (4-5): 388-402. https://doi.org/10.1669/0883-1351 (2003)018<0388:ETMMTM>2.0.CO;2.

Ezaki, Y., J.B. Liu, N. Adachi, and Z. Yan. 2017. Microbialite development during the protracted inhibition of skeletal-dominated reefs in the
Zhangxia Formation (Cambrian Series 3) in Shandong Province, North China. Palaios 32 (9): 559-571. https://doi.org/10.2110/palo.2016.097.

Ezaki, Y., J.B. Liu, T. Nagano, and N. Adachi. 2008. Geobiological aspects of the earliest Triassic microbialites along the southern periphery of the tropical Yangtze platform: Initiation and cessation of a microbial regime. Palaios 23 (6): 356-369. https://doi.org/10.2110/palo.2007.p07-035r.

Grotzinger, J., and Z. Al-Rawahi. 2014. Depositional facies and platform architecture of microbialite-dominated carbonate reservoirs, EdiacaranCambrian Ara Group, Sultanate of Oman. AAPG Bulletin 98 (8): 14531494. https://doi.org/10.1306/02271412063.

Grotzinger, J.P., and A.H. Knoll. 1999. Stromatolites in Precambrian carbonates: Evolutionary mileposts or environmental dipsticks? Annual Review of Earth and Planetary Sciences 27 (1): 313-358. https://doi.org/1 0.1146/annurev.earth.27.1.313.

Han, Z.Z., Y.Y. Zhao, H.X. Yan, H. Zhao, M. Han, B. Sun, R.R. Meng, D.X. Zhuang, D. Li, W.J. Gao, S.Y. Du, X.A. Wang, K.X. Fan, W.Y. Hu, and M.X Zhang. 2017. The characterization of intracellular and extracellular biomineralization induced by Synechocystis sp. PCC6803 cultured under low Mg/Ca ratios conditions. Geomicrobiology Journal 34 (4): 362-373. https://doi.org/10.1080/01490451.2016.1197986.

Jahnert, R.J., and L.B. Collins. 2011. Significance of subtidal microbial deposits in Shark Bay, Australia. Marine Geology 286 (1-4): 106-111. https://doi.org/10.1016/j.margeo.2011.05.006.

Jiang, H.X., and Y.S. Wu. 2007. Restudy of the microbialite from the Permian-Triassic boundary section, Chongqing. Acta Petrologica Sinica 23 (5): 1189-1196. https://doi.org/10.3321/j.issn:1000-0569.2007.05.032 (in Chinese with English abstract).

Kalkowsky, E. 1908. Oolith and stromatolith in norddeutschen Buntsandstein. Zeitschrift der Deutschen Geologischen Gesellschaft 60: 68-125.

Kaźmierczak, J., T. Fenchel, M. Kühl, S. Kempe, B. Kremer, B. Łącka, and K. Małkowski. 2015. $\mathrm{CaCO}_{3}$ precipitation in multilayered cyanobacterial mats: Clues to explain the alternation of micrite and sparite layers in calcareous stromatolites. Life 5 (1): 744-769. https://doi.org/10.3390/ life5010744.

Kennard, J.M., and N.P. James. 1986. Thrombolites and stromatolites: Two distinct types of microbial structures. Palaios 1 (5): 492-503. https://doi. org/10.2307/3514631.

Kershaw, S., S. Crasquin, Y. Li, P.Y. Collin, M.B. Forel, X.N. Mu, A. Baud, Y. Wang, S. Xie, F. Maurer, and L. Guo. 2012. Microbialites and global environmental change across the Permian-Triassic boundary: A synthesis. Geobiology 10 (1): 25-47. https://doi.org/10.1111/j.1472-4669.2 011.00302.x.

Kershaw, S., Y. Li, S. Crasquin-Soleau, Q.L. Feng, X.N. Mu, P.Y. Collin, A. Reynolds, and L. Guo. 2007. Earliest Triassic microbialites in the South China block and other areas: Controls on their growth and distribution Facies 53 (3): 409-425. https://doi.org/10.1007/s10347-007-0105-5.

Kranz, S.A., D. Wolf-Gladrow, G. Nehrke, G. Langer, and B. Rosta. 2010. Calcium carbonate precipitation induced by the growth of the marine cyanobacteria Trichodesmium. Limnology and Oceanography 55 (6): 2563-2569. https://doi.org/10.4319/lo.2010.55.6.2563.

Lee, J.H., J.T. Chen, S.J. Choh, D.J. Lee, Z.Z. Han, and S.K. Chough. 2014. Furongian (Late Cambrian) sponge-microbial maze-like reefs in the North China platform. Palaios 29 (1): 27-37. https://doi.org/10.2110/pa lo.2013.050.

Liang, A.Q., C. Paulo, Y. Zhu, and M. Dittrich. 2013. $\mathrm{CaCO}_{3}$ biomineralization on cyanobacterial surfaces: Insights from experiments with three Synechococcus strains. Colloids and Surfaces B: Biointerfaces 111: 600-608. https://doi.org/10.1016/j.colsurfb.2013.07.012.

Liu, J.B., Y. Ezaki, S.R. Yang, H.F. Wang, and N. Adachi. 2007. Age and sedimentology of microbialites after the end-Permian mass extinction in Luodian, Guizhou Province. Journal of Palaeogeography (Chinese Edition) 9 (5): 473-486. https://doi.org/10.3969/j.issn.1671-1505.2007.05.005 (in Chinese with English abstract).

Liu, S.G., J.M. Song, P. Luo, H.R. Qing, T. Lin, W. Sun, Z.W. Li, H. Wang, H.L. Peng, Y.Q. Yu, Y. Long, and Y.B. Wan. 2016. Characteristics of microbial carbonate reservoir and its hydrocarbon exploring outlook in the Sichuan Basin, China. Journal of Chengdu University of Technology 
(Science and Technology Edition) 43 (2): 129-152. https://doi.org/10.3969/ j.issn.1671-9727.2016.02.01 (in Chinese with English abstract).

Lowenstam, H.A., and S. Weiner. 1989. On Biomineralization, 324 pp. New York: Oxford University Press. https://doi.org/10.1093/oso/978019504 9770.001.0001

McConnaughey, T. 1989. Biomineralization mechanisms. In Origin, Evolution, and Modern Aspects of Biomineralization in Plants and Animals, ed. R.E. Crick, pp. 57-73. Boston: Springer. https://doi.org/10.1007/978-1-47576114-6_5.

Obst, M., B. Wehrli, and M. Dittrich. 2009. $\mathrm{CaCO}_{3}$ nucleation by cyanobacteria: Laboratory evidence for a passive, surface-induced mechanism. Geobiology 7 (3): 324-347. https://doi.org/10.1111/j.1472-4 669.2009.00200.x.

Patterson, M. 2014. Geomicrobial Investigation of Thrombolites in Green Lake, New York and Highborne Cay, Bahamas [master thesis], pp. 1-133. Connecticut: University of Connecticut.

Planavsky, N., and R.N. Ginsburg. 2009. Taphonomy of modern marine Bahamian microbialites. Palaios 24 (1): 5-17. https://doi.org/10.2110/pa lo.2008.p08-001r.

Reid, R.P., N.P. James, I.G. Macintyre, C.P. Dupraz, and R.V. Burne. 2003. Shark Bay stromatolites: Microfabrics and reinterpretation of origins. Facies 49 (1): 299-324. https://doi.org/10.1007/s10347-003-0036-8.

Reid, R.P., I.G. Macintyre, K.M. Browne, R.S. Steneck, and T. Miller. 1995. Modern marine stromatolites in the Exuma cays, Bahamas: Uncommonly common. Facies 33 (1): 1-17. https://doi.org/10.1007/BF02 537442

Reid, R.P., I.G. Macintyre, and R.S. Steneck. 1999. A microbialite/algal ridge fringing reef complex, Highborne cay, Bahamas. Atoll Research Bulletin 465: 1-18. https://doi.org/10.5479/si.00775630.465.1.

Reid, R.P., P.T. Visscher, A.W. Decho, J.F. Stolz, B.M. Bebout, C. Dupraz, I.G. Macintyre, H.W. Paerl, J.L. Pinckney, L. Prufert-Bebout, T.F. Steppe, and D. J. DesMarais. 2000. The role of microbes in accretion, lamination and early lithification of modern marine stromatolites. Nature 406 (6799): 989-992. https://doi.org/10.1038/35023158.

Riding, R. 1977. Calcified Plectonema (blue-green algae), a recent example of Girvanella from Aldabra atoll. Palaeontology 20 (1): 33-46.

Riding, R. 1991. Classification of microbial carbonates. In Calcareous Algae and Stromatolites, ed. R. Riding, pp. 21-51. Berlin: Springer-Verlag. https://doi.org/10.1007/978-3-642-52335-9_2.

Riding, R. 2006. Cyanobacterial calcification, carbon dioxide concentrating mechanisms, and Proterozoic-Cambrian changes in atmospheric composition. Geobiology 4 (4): 299-316. https://doi.org/10.1111/j.1472-4 669.2006.00087.x.

Riding, R. 2011. Microbialites, stromatolites, and thrombolites. In Encyclopedia of Geobiology, Encyclopedia of Earth Science Series, ed. J. Reitner and V. Thiel, pp. 635-654. Heidelberg: Springer. https://doi.org/1 0.1007/978-1-4020-9212-1_196.

Shapiro, R.S., and S.M. Awramik. 2000. Microbialite morphostratigraphy as a tool for correlating Late Cambrian-Early Ordovician sequences. The Journal of Geology 108 (2): 171-180. https://doi.org/10.1086/314394.

Song, J.M., P. Luo, S.S. Yang, X.F. Zhai, G. Zhou, and P.P. Lu. 2012. Carbonate rock microbial construction of the Lower Cambrian Xiaoerblak Formation in Sugaitblak area, Tarim Basin. Journal of Palaeogeography (Chinese Edition) 14 (3): 341-354 (in Chinese with English abstract).

Suosaari, E.P., R.P. Reid, T.A.A. Araujo, P.E. Playford, D.K. Holley, K.J. McNamara, and G.P. Eberli. 2016. Environmental pressures influencing living stromatolites in Hamelin Pool, Shark Bay, western Australia. Palaios 31 (10): 483-496. https://doi.org/10.2110/palo.2016.023.

Theisen, C.H., and D.Y. Sumner. 2016. Thrombolite fabrics and origins: Influences of diverse microbial and metazoan processes on Cambrian thrombolite variability in the Great Basin, California and Nevada. Sedimentology 63 (7): 2217-2252. https://doi.org/10.1111/sed.12304.

Wang, H.F., J.B. Liu, and Y. Ezaki. 2012. Sea-level changes at the Dawen Permian-Triassic boundary section of Luodian, Guizhou Province, South China: A global correlation. Acta Scientiarum Naturalium Universitatis Pekinensis 48 (4): 589-602 (in Chinese with English abstract).
Wang, J., R.L. Zhuang, K.T. Lao, and G.H. Long. 1990. Division and geological implications of calcareous algal morphological groups and environmental zones in the Lower Cambrian Qingxudong Formation, Huayuan district, western Hunan. Sedimentary Facies and Palaeogeography 10 (3): 9-19 (in Chinese with English abstract).

Wang, M.M., L. Yang, X.Y. Xu, W. Zhang, and L.Q. Wang. 2017. Geitlerinema ionicum - A newly recorded genus and species of Cyanophyta in China. Journal of Shanghai Ocean University 26 (2): 258-262. https://doi. org/10.12024/jsou.20160601805 (in Chinese with English abstract).

Wang, Y.B., J.N. Tong, J.S. Wang, and X.G. Zhou. 2005. Calcimicrobialite after end-Permian mass extinction in South China and its palaeoenvironmental significance. Chinese Science Bulletin 50 (7): 665671. https://doi.org/10.1360/982004-323.

Webb, G.E. 2001. Biologically induced carbonate precipitation in reefs through time. In The History and Sedimentology of Ancient Reef Systems, ed. G.D. Stanley Jr., 159-203. New York: Springer.

Wu, Y.S., H.X. Jiang, G.L. Yu, and L.J. Liu. 2018. Conceptions of microbialites and origin of the Permian-Triassic boundary microbialites from Laolongdong, Chongqing, China. Journal of Palaeogeography (Chinese Edition) 20 (5): 737-775. https://doi.org/10.7605/gdlxb.2018.05.053 (in Chinese with English abstract).

Wu, Y.S., G.L. Yu, R.H. Li, L.R. Song, H.X. Jiang, R. Riding, L.J. Liu, D.Y. Liu, and R. Zhao. 2014. Cyanobacterial fossils from $252 \mathrm{Ma}$ old microbialites and their environmental significance. Scientific Reports 4 (3820): 1-5.

Wu, Y.Y., T.S. Zhang, J.L. Lü, and Y. Liu. 2017. The sedimentological characteristics of microbialites of the Cambrian in the vicinity of Beijing, China. Journal of Palaeogeography 6 (2): 117-131. https://doi.org/10.101 6/j.jop.2017.03.003.

Yan, H.X., Z.Z. Han, H. Zhao, S.X. Zhou, N.J. Chi, M. Han, X.Y. Kou, Y. Zhang, L. L. Xu, C.C. Tian, and S. Qin. 2014. Characterization of calcium deposition induced by Synechocystis sp. PCC6803 in BG11 culture medium. Chinese Journal of Oceanology and Limnology 32 (3): 503-510. https://doi.org/1 0.1007/s00343-014-3150-2.

Yan, Z., J.B. Liu, Y. Ezaki, N. Adachi, and S.X. Du. 2017. Stacking patterns and growth models of multiscopic structures within Cambrian Series 3 thrombolites at the Jiulongshan section, Shandong Province, northern China. Palaeogeography, Palaeoclimatology, Palaeoecology 474: 45-57. https://doi.org/10.1016/j.palaeo.2016.07.009.

Yang, H., S.X. Zhang, H.S. Jiang, and Y.B. Wang. 2006. Age and general characteristics of calcimicrobialite near the Permian-Triassic boundary in Chongyang, Hubei Province. Earth Science - Journal of China University of Geosciences 31 (2): 165-170. https://doi.org/10.3321/j.issn:1000-2383.2 006.02 .004 (in Chinese with English abstract).

You, X.L., S. Sun, and J.Q. Zhu. 2014. Significance of fossilized microbes from the Cambrian stromatolites in the Tarim Basin, Northwest China. Science China Earth Sciences 57 (12): 2901-2913. https://doi.org/10.1007/s11430014-4935-z.

Zhang, X.L., D.G. Shu, J. Han, Z.F. Zhang, J.N. Liu, and D.J. Fu. 2014. Triggers for the Cambrian explosion: Hypotheses and problems. Gondwana Research 25 (3): 896-909. https://doi.org/10.1016/j.gr.2013.06.001.

Zheng, J.F., Y.Q. Chen, L.L. Huang, W. Yan, X.F. Ni, B.H. Li, and X.Y. Guo. 2019. Reservoir modeling of the Lower Cambrian Xiaoerblak Formation in the Sugaitblak section and its significance for exploring regions in the Tarim Basin, NW China. Acta Sedimentologica Sinica 37 (3): 601-609 (in Chinese with English abstract).

Zhu, T.T., and M. Dittrich. 2016. Carbonate precipitation through microbial activities in natural environment, and their potential in biotechnology: A review. Frontiers in Bioengineering and Biotechnology 4: 4. https://doi. org/10.3389/fbioe.2016.00004.

\section{Publisher's Note}

Springer Nature remains neutral with regard to jurisdictional claims in published maps and institutional affiliations. 